CLINICAL STUDY

\title{
Plasma dipeptidyl peptidase-IV activity in patients with type-2 diabetes mellitus correlates positively with HbAlc levels, but is not acutely affected by food intake
}

\author{
Jakob Ryskjær, Carolyn F Deacon ${ }^{1}$, Richard D Carr ${ }^{2}$, Thure Krarup, Sten Madsbad ${ }^{3}$, Jens Holst ${ }^{1}$ \\ and Tina Vilsbøll \\ Department of Internal Medicine F, Gentofte Hospital, University of Copenhagen, Niels Andersens Vej 65, DK-2900 Hellerup, Denmark, ${ }^{1}$ Department of \\ Medical Physiology, The Panum Institute, Copenhagen, Denmark, ${ }^{2}$ Novo Nordisk A/S, Bagsvard, Denmark and ${ }^{3}$ Department of Endocrinology, Hvidovre
} Hospital, Hvidovre, Denmark

(Correspondence should be addressed to T Vilsboll; Email: t.vilsboll@dadlnet.dk)

\begin{abstract}
Objective: Glucagon-like peptide-1 (GLP-1) and glucose-dependent insulinotropic polypeptide are incretin hormones, secreted in response to meal ingestion. The incretin hormones stimulate insulin secretion and are essential for the maintenance of normal plasma glucose concentrations. Both incretin hormones are metabolized quickly by the enzyme dipeptidyl peptidase-IV (DPP-IV). It is well known that type-2 diabetic patients have an impaired incretin effect. Therefore, the aim of the present study was to investigate plasma DPP-IV activity in the fasting and the postprandial state in type- 2 diabetic patients and control subjects.

Design: The study included two protocols. Protocol one involved 40 fasting type- 2 diabetic patients (28 men); age $61 \pm 1.4$ (mean \pm s.e.m.) years; body mass index (BMI) $31 \pm 0.6 \mathrm{~kg} / \mathrm{m}^{2}$; HbAlc $7.2 \pm 0.2 \%$; and 20 matched control subjects ( $14 \mathrm{men})$ were studied. Protocol two involved eight type2 diabetic patients (six men); age $63 \pm 1.2$ years; BMI $33 \pm 0.5 \mathrm{~kg} / \mathrm{m}^{2}$; HbAlc $7.5 \pm 0.4 \%$; eight matched control subjects were included.

Methods: In protocol one, fasting values of DPP-IV activity were evaluated and in protocol two, postprandial DPP-IV activity during a standard meal test $(566 \mathrm{kcal})$ was estimated.

Results: Mean fasting plasma DPP-IV activity (expressed as degradation of GLP-1) was significantly higher in this patient group compared with the control subjects $(67.5 \pm 1.9$ vs $56.8 \pm 2.2 \mathrm{fmol}$ GLP-1/h (mean \pm s.e.m.); $P=0.001$ ). In the type- 2 diabetic patients, DPP-IV activity was positively correlated to FPG and HbAlc and negatively to the duration of diabetes and age of the patients. No postprandial changes were seen in plasma DPP-IV activity in any of the groups.

Conclusions: Plasma DPP-IV activity increases in the fasting state and is positively correlated to FPG and HbAlc levels, but plasma DPP-IV activity is not altered following meal ingestion and acute changes in plasma glucose.
\end{abstract}

European Journal of Endocrinology 155 485-493

\section{Introduction}

The two major incretin hormones, glucagon-like peptide (GLP-1) and glucose-dependent insulinotropic polypeptide (GIP, previously known as gastric inhibitory polypeptide), are secreted from the small intestine in response to meal ingestion and act on specific receptors on the $\beta$-cells. Both are metabolized by the enzyme dipeptidyl peptidase-IV (DPP-IV) $(1,2)$, which is primarily found not only in the brush-border membranes of the kidney and the small intestine, but also in other tissues (e.g. hepatocytes around bile canaliculi, epithelial cells of the pancreas, and in capillary endothelium), and in a soluble form in plasma (3). DPP-IV cleaves GLP-1 and GIP at the $\mathrm{N}$ terminus, resulting in the formation of metabolites, which lack insulinotropic activity (4). The cleavage can be blocked by specific DPP-IV inhibitors, resulting in increased plasma concentrations of the intact peptides $(5,6)$ and improved glucose tolerance (7). Therefore, DPP-IV inhibitors have been proposed as a possible pharmacological treatment of type-2 diabetes (8), and many compounds are presently in clinical development (9). The effect of GIP and GLP-1 is essential for the maintenance of normal glucose tolerance. In 1986, Nauck et al. showed that type-2 diabetic patients have a markedly impaired incretin effect, which may contribute to the relative insulin deficiency seen in these patients (10). Clinical studies suggest that a reduced postprandial secretion of GLP-1 $(11,12)$ combined with an 
impaired insulinotropic effect of GIP $(13,14)$ contribute to the impaired incretin effect in type-2 diabetic patients. Pilot studies carried out in animal models of type-2 diabetes have demonstrated that plasma DPP-IV activity levels correlate positively with plasma glucose and HbAlc and negatively with plasma insulin levels, raising the possibility that endogenous DPP-IV activity may influence glucose homeostasis by altering the levels of intact (insulinotropic) incretin hormones. Few clinical studies examining plasma DPP-IV activity levels in patients with type-2 diabetes have reported unchanged (15), increased (16), and decreased (17, 18) plasma activity. Urinary DPP-IV activity has been shown to correlate positively with worsening glucose tolerance $(19,20)$. The aim of the present study was, therefore, to investigate plasma DPP-IV activity in the fasting state and evaluate whether plasma DPP-IV activity per se is acutely regulated during meal ingestion, both in patients with type-2 diabetes and in control subjects. Theoretically, acute changes in the concentrations of intact and total forms of incretin hormones during meal ingestion could be a result of either changes in hormone release or changes in the mechanisms responsible for their processing within, or removal from, the circulation. Furthermore, we evaluated whether a relationship between plasma DPP-IV activity and plasma glucose, insulin, incretin hormone concentrations and HbAlc could be found in the diabetic patients. Finally, since it has been suggested that metformin may have effects on both plasma DPP-IV activity $(21,22)$ and GLP-1 secretion $(23,24)$, the possible effects of metformin were also assessed.

\section{Material and methods}

\section{Subjects}

The study was divided into two protocols. Protocol one involved 40 fasting type- 2 diabetic patients ( 28 men, 12 women; age (mean \pm s.E.м.) $61 \pm 1.4$ years; body mass index (BMI) $30.8 \pm 0.6 \mathrm{~kg} / \mathrm{m}^{2}$; and HbAlc $7.2 \pm 0.2 \%$ ) and 20 control subjects, matched for age, gender, and BMI (14 men, 6 women; age $60 \pm 2.0$ years; BMI $30.9 \pm 0.9 \mathrm{~kg} / \mathrm{m}^{2}$; and HbAlc $5.4 \pm 0.1 \%$ ). Sixteen patients were treated with diet alone, and 24 treated with diet and oral antidiabetic medications (sulphonylurea and/or biguanides). Twenty-six patients had a history of hypertension and were treated with ACE inhibitors, thiazides, and/or calcium antagonists. In protocol two, eight type-2 diabetic patients (six men, two women; mean age $62.5 \pm 1.2$ years, BMI $32.7 \pm$ $0.5 \mathrm{~kg} / \mathrm{m}^{2}$; and HbAlc $7.5 \pm 0.4 \%$ ) and eight control subjects (six men, two women; mean age 60土1.2 years, BMI $32.9 \pm 0.7 \mathrm{~kg} / \mathrm{m}^{2}$; and HbAlc $5.5 \pm 0.1 \%$ ) were selected from protocol one and studied during a standard breakfast meal test. The participants for protocol two were selected to have a BMI between 30 and $35 \mathrm{~kg} / \mathrm{m}^{2}$. Three patients were treated with diet alone, whereas five were treated with both diet and oral antidiabetic medication. All type-2 diabetic patients were diagnosed according to the criteria of the World Health Organization (25). No patient had albuminuria above $300 \mathrm{mg} /$ day or proliferative retinopathy and all had normal liver function and were without history of gastrointestinal diseases. All control subjects were without family history of type-2 diabetes and all had a normal $75 \mathrm{~g}$ oral glucose tolerance test, which was carried out immediately before inclusion in the study. All agreed to participate and gave oral and written consent. The study was approved by the Copenhagen County Ethical Committee on 31 January 2002 (Journal numbers in the committee: KA01175), and the study was conducted according to the Helsinki Declaration.

The subjects studied were chosen to represent typical obese type-2 diabetic outpatients and all were kept on their regular oral antidiabetic medication, which was continued until the evening before the study.

\section{Methods}

Protocol one: after an overnight fast, blood samples were collected in fluoride tubes for measurement of plasma glucose, in precooled glass tubes containing EDTA plus DPP-IV inhibitor (valine-pyrrolidide; $0.01 \mathrm{mmol} / \mathrm{l}$, final concentration) and aprotinin $(500 \mathrm{KIU} / \mathrm{ml}$ blood; Trasylol; Bayer) for incretin hormone measurements, and in precooled glass tubes containing heparin plus aprotinin for insulin, C-peptide, and DPP-IV activity measurements. Blood samples were immediately centrifuged at $4{ }^{\circ} \mathrm{C}$ and the plasma was stored at 20 (incretin hormones) and $80^{\circ} \mathrm{C}$ (insulin, C-peptide and DPP-IV activity) until analysis.

Protocol two: After a 10-h overnight fast, a cannula was inserted into a cubital vein for blood sampling during the study. The test meal (34\% fat, $47 \%$ carbohydrate, $19 \%$ protein, a total of $566 \mathrm{kcal}$ $(2730 \mathrm{~kJ}))$, consisted $50 \mathrm{~g}$ white bread, $50 \mathrm{~g}$ black bread, $10 \mathrm{~g}$ butter, $40 \mathrm{~g}$ cheese, $20 \mathrm{~g}$ sugar-free jam, and $200 \mathrm{ml}$ milk. The meal was consumed within $15 \mathrm{~min}$. Blood samples were drawn 15, 10, and 0 min before ingestion of the meal and again $15,30,45,60$, $75,90,120,150$, and $180 \mathrm{~min}$ after ingestion. Blood samples were collected in accordance with the procedure described under protocol one.

\section{Analysis}

Plasma glucose concentrations were measured during the experiment using a glucose oxidase method in a glucose analyzer (Yellow Springs Instrument model: YSI 2300 STAT plus analyser; Yellow Springs, Ohio, USA). Plasma samples were assayed for total GLP-1 immunoreactivity, as previously described by Ørskov et al. (26), using a RIA (antiserum no. 89 390), which is specific for the C-terminal of the GLP-1 molecule. Intact 
GLP-1 was measured using an ELISA, as previously described (27). The assay is a two-site sandwich assay using two monoclonal antibodies; GLP-1F5 as the catching antibody (C-terminally directed) and Mab26.1 as the detecting antibody (N-terminally directed) (28). Total GIP was measured, as described previously, using the C-terminally directed antiserum R65 (29, 30), which reacts completely with intact GIP and the N-terminally truncated metabolite. Intact, biologically active, GIP was measured as described previously (2), using antiserum no. 98171.

Plasma insulin and C-peptide concentrations were measured using commercial AutoDELFIA Time-resolved fluoroimmunoassay (Wallac Oy, Turku, Finland), as described previously (11). DPP-IV activity was assessed as described previously (6), using a bioassay method that is based on the fact that DPP-IV is the sole enzyme responsible for $\mathrm{NH}_{2}$-terminal degradation of GLP-1 in plasma $(31,32)$. Briefly, GLP-1(7-37) (5 $\mu \mathrm{l}, 100 \mathrm{fmol})$ was added to plasma samples $(95 \mu \mathrm{l})$ and incubated for $1 \mathrm{~h}$ at $37^{\circ} \mathrm{C}$, after which the amount of GLP-1 that remained undegraded was determined by the ELISA method using a MAB (Mab26.1) that is specific for the intact peptide (6). As a reference, GLP-1 (5 $\mu \mathrm{l}, 100 \mathrm{fmol})$ was added to heat-inactivated plasma $(95 \mu \mathrm{l})$, which contained $0.01 \mathrm{mmol} / \mathrm{l}$ valine-pyrrolidide and $500 \mathrm{KIU} /$ $\mathrm{ml}$ aprotinin. By defining the DPP-IV activity in the reference as zero and comparing the amount of intact GLP-1 in the samples with the reference, the DPP-IV activity was expressed as the percentage of GLP-1 being degraded over $60 \mathrm{~min}$. The minimum detectable difference in DPP-IV activity was $3.2 \mathrm{fmol}$ GLP-1/h (i.e. $3.2 \%$ of $100 \mathrm{fmol}$ GLP-1/h). HbAlc was measured using a colorimetric method (normal range $<6 \%$ ).

\section{Statistical analysis and calculations}

The results from protocol one are presented as means and ranges. Statistical analysis (Student's $t$-test for unpaired data for comparison of patient results versus control subjects and multivariate analysis) was carried out using the Statistica software (Statsoft, Tulsa, OK, USA). The results from protocol two are presented as means \pm s.e.m. and statistical analysis was carried out as a two-factor ANOVA for repeated measurements of patient results vs control subjects, also using Statistica. In addition, the area under the curve (AUC), total and incremental, was calculated for plasma DPP-IV activity, total and intact GIP, total and intact GLP-1, insulin, and C-peptide. A quantitative assessment of insulin resistance (IR) was made by comparing the subjects fasting insulin (FI) and fasting plasma glucose (FPG) using homeostatic model assessment (HOMA). The formula is as follows: $\mathrm{IR}=(\mathrm{FI} \times$ FPG)/22.5; where FI, fasting insulin (U/ml) and FPG, fasting plasma glucose $(\mathrm{mmol} / \mathrm{l})$.

\section{Results \\ Protocol one}

Plasma glucose, insulin, and C-peptide FPG, insulin, and C-peptide concentrations were significantly higher in the type-2 diabetic patients compared with control subjects (Table 1). HOMA analysis revealed a higher IR in the type-2 diabetic patients compared with the control subjects $(4.7 \pm 0.4$ vs $2.1 \pm 0.2$ (mean \pm s.Е.м.); $P<0.001)$.

Incretin hormones Significantly higher concentrations of both intact GIP and intact GLP-1 were seen in the type-2 diabetic patients compared with control subjects $(P=0.028$ and 0.017 respectively (Table 1$)$ ). Total GIP and GLP-1 concentrations were similar in the two groups. No correlation between fasting levels of incretin hormones to plasma DPP-IV activity was found (data not shown). As a measure for DPP-IV degradation of the incretin hormones ratios between intact/total were calculated. However, there was no correlation between these ratios and plasma DPP-IV activity.

DPP-IV activity The mean fasting plasma DPP-IV activity was significantly higher in the patient group compared with the control subjects $(67.5 \pm 1.9$ vs $56.8 \pm 2.2 \mathrm{fmol}$ GLP- $1 / \mathrm{h}$ (mean \pm s.E.M.) respectively; $P=0.001)$. In the patient group, a positive correlation was seen between DPP-IV activity and plasma glucose, HbAlc, insulin, and C-peptide concentrations (Fig. 1). A negative correlation was found between plasma DPP-IV activity and duration of diabetes, as well as the age of the patients (Fig. 1). No correlation was seen between DPP-IV activity and BMI. Multiple linear regression

Table 1 Fasting results in type-2 diabetic patients and control subjects.

\begin{tabular}{lcccccccc}
\hline & $\begin{array}{c}\text { PG } \\
(\mathrm{mmol} / \mathrm{l})\end{array}$ & $\begin{array}{c}\text { p-DPP-IV } \\
\text { activity } \\
(\mathrm{fmol} \text { GLP-1/h) }\end{array}$ & $\begin{array}{c}\text { Insulin } \\
(\mathrm{pmol} / \mathrm{l})\end{array}$ & $\begin{array}{c}\text { C-peptide } \\
(\mathrm{pmol} / \mathrm{l})\end{array}$ & $\begin{array}{c}\text { GIP, total } \\
(\mathrm{pmol} / \mathrm{l})\end{array}$ & $\begin{array}{c}\text { GIP, intact } \\
(\mathrm{pmol} / \mathrm{l})\end{array}$ & $\begin{array}{c}\text { GLP-1, } \\
\text { total } \\
(\mathrm{pmol} / \mathrm{l})\end{array}$ & $\begin{array}{c}\text { GLP-1, intact } \\
(\mathrm{pmol} / \mathrm{l})\end{array}$ \\
\hline $\begin{array}{l}\text { Type-2 } \\
\text { diabetic patients }\end{array}$ & $8.6 \pm 0.4$ & $67.5 \pm 1.9$ & $74.5 \pm 6.0$ & $1082 \pm 61$ & $9.7 \pm 1.6$ & $22.8 \pm 1.7$ & $7.3 \pm 0.6$ & $9.0 \pm 1.2$ \\
$\begin{array}{l}\text { Healthy } \\
\text { subjects }\end{array}$ & $5.4 \pm 0.1$ & $56.8 \pm 2.2$ & $52.3 \pm 5.9$ & $754 \pm 72$ & $3.7 \pm 1.5$ & $19.0 \pm 1.1$ & $4.9 \pm 0.9$ & $9.0 \pm 3.5$ \\
& $(P<0.001)$ & $(P=0.001)$ & $(P=0.022)$ & $(P=0.002)$ & $(P=0.017)$ & $(P=0.134)$ & $(P=0.028)$ & $(P=0.99)$ \\
\hline
\end{tabular}

PG, plasma glucose; p-DPP-IV, plasma dipeptidyl peptidase-IV; GIP, glucose-dependent insulinotropic polypeptide; GLP-1, glucagon-like peptide-1. 
analysis, with plasma glucose, insulin, C-peptide, HbAlc, age, and duration of diabetes as putative determinants of DPP-IV activity and GLP-1 levels were performed. Insulin and age were significant covariates for DPP-IV activity.

Effects of metformin The patient group was also subdivided according to whether they were treated with metformin or not (Table 2). Analysis of these sub-groups revealed no significant differences in DPP-IV activity or total and intact GLP-1 levels $(P=0.48,0.66,0.78$ respectively). However, both total and intact GIP concentrations were higher in the group receiving metformin ( $P=0.002,0.004$ respectively). Multivariate analysis was performed in order to rule out the possibility that confounders (HbAlc, age, duration of diabetes, and BMI) prevented the observation of any significant difference between metformin-treated patients, but no differences were found.

\section{Protocol two - meal test}

Plasma glucose, insulin, and C-peptide Plasma glucose concentrations are shown in Fig. 2. In the patient group, the peak of postprandial insulin concentrations (mean \pm s.e.m.) was seen at $60 \mathrm{~min}(398 \pm 94 \mathrm{pmol} / \mathrm{l})$ and peak C-peptide concentration occurred after $150 \mathrm{~min}$ $(2701 \pm 339 \mathrm{pmol} / \mathrm{l})$. Corresponding results in control subjects were (peak values after $60 \mathrm{~min}$ ) $469 \pm 280$ and $2742 \pm 355 \mathrm{pmol} / \mathrm{l}$ respectively (Fig. 2). No significant differences in $\mathrm{AUC}_{\text {insulin }}$ or $\mathrm{AUC}_{\mathrm{C} \text {-peptide }}$ were seen when comparing type-2 diabetic patients with control subjects. HOMA-analysis revealed a significantly higher IR in the
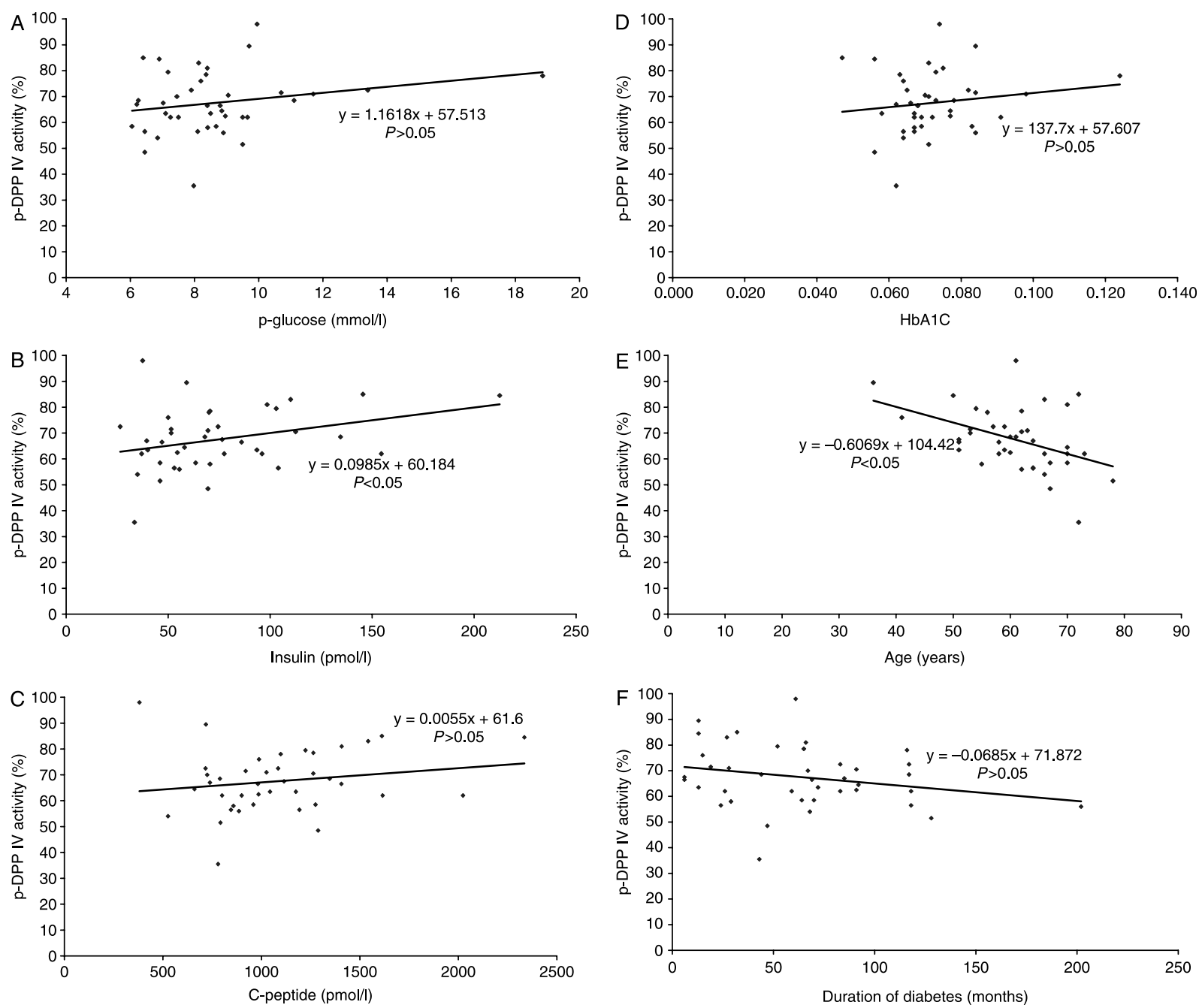

Figure 1 Graphs showing associations between plasma DPP-IV activity and (A) plasma glucose, (B) insulin, (C) C-peptide, (D) HbAlc, (E) age, and $(F)$ duration of diabetes. 
type-2 diabetic patients compared with the control subjects $(6.8 \pm 1.7$ vs $2.8 \pm 0.7 ; P=0.04)$.

Incretin hormones Baseline total and intact GIP concentrations (mean \pm s.e.m.) were $8.6 \pm 2.1$ and $7.4 \pm 0.8 \mathrm{pmol} / \mathrm{l}$ respectively in the patient group. Corresponding results for the control subjects were $7.4 \pm 2.0$ and $6.0 \pm 1.2 \mathrm{pmol} / \mathrm{l}$ respectively (Fig. 3). Peak concentrations of total and intact GIP occurred at 60 and $45 \mathrm{~min}$ in the patient group respectively after meal ingestion and amounted to $138 \pm 16$ and $65 \pm 10 \mathrm{pmol} / \mathrm{l}$. In the control subjects, the corresponding results were $131 \pm 11$ and $61 \pm 6 \mathrm{pmol} / \mathrm{l}$ respectively with peak concentrations also at 60 and $45 \mathrm{~min}$. In the group of type- 2 diabetic patients, the mean basal total GLP-1 was $23.4 \pm 0.9 \mathrm{pmol} / \mathrm{l}$ compared to $19.9 \pm 1.7 \mathrm{pmol} / \mathrm{l}$ in the matched control subjects (NS). Peak total GLP-1 concentrations occurred at $45(38.8 \pm 3.6 \mathrm{pmol} / \mathrm{l})$ and $90 \mathrm{~min}(30.9 \pm 2.4 \mathrm{pmol} / \mathrm{l})$ in the patients and matched control subjects group respectively (Fig. 3). In both groups, both GLP-1 and GIP concentrations returned toward basal levels at the end of the experiment. Total and intact GIP AUC showed no significant differences between diabetic patients and control subjects. Total and incremental $\mathrm{AUC}_{\mathrm{GLP}-1}$ (total), 0-180 min were not significantly different between the groups ((mean \pm s.E.M., patients versus control subjects) $5950 \pm 660$ vs $4877 \pm$ $285 \mathrm{~min}$ pmol per $\mathrm{l}(P=0.158)$ and $1735 \pm 560$ vs $1296 \pm 402$ min pmol per l $(P=0.54)$ respectively $)$. Total and incremental $\mathrm{AUC}_{\mathrm{GLP}-1}$ (intact), 0-180 min were not significant different when comparing the control subjects with the type- 2 diabetics $(706 \pm 103$ vs $437 \pm$ 146 min pmol per $l(P=0.48)$ and $100 \pm 83$ vs $322 \pm$ $89 \mathrm{~min}$ pmol per l $(P=0.33)$ respectively). No correlation between incremental AUC ratios (intact/total) and DPP-IV activity was found.

DPP-IV activity Plasma DPP-IV activity was slightly higher (though not statistically significant), both in the fasting state as well as postprandial, in the type- 2 diabetic patients compared with the control subjects (Fig. 4). Significant changes in the DPP-IV activity after the ingestion of the breakfast meal were not seen in either of the groups. No difference in AUC was seen between the type-2 diabetics and the control subjects (NS).

\section{Discussion}

Previous studies have shown that the incretin hormones, GIP and GLP-1, stimulate insulin secretion and are essential for the maintenance of normal plasma glucose concentrations. It has also been shown that 
type-2 diabetic patients have an impaired incretin effect. Since both incretin hormones are metabolized quickly by the enzyme DPP-IV, this raises the possibility that an increase in DPP-IV concentration and/or activity may contribute to the impaired incretin effect found in the patients. In the fasting study (protocol one), plasma DPP-IV activity was significantly higher in the patients compared with controls, and a similar tendency was seen before the meal test (protocol two), in agreement with the study of Mannucci et al. (16), but in contrast to those of Korosi et al. (17) and Meneilly et al. (18), who reported decreased levels. According to Mannucci et al. (16), plasma DPP-IV activity is related to the prevailing glycemic control, with significant elevations in activity first becoming apparent as HbAlc levels increase above $8.5 \%$, which may, at least partially, explain some of the apparent conflicting results to be found in the literature, since the patients in the studies reporting decreased
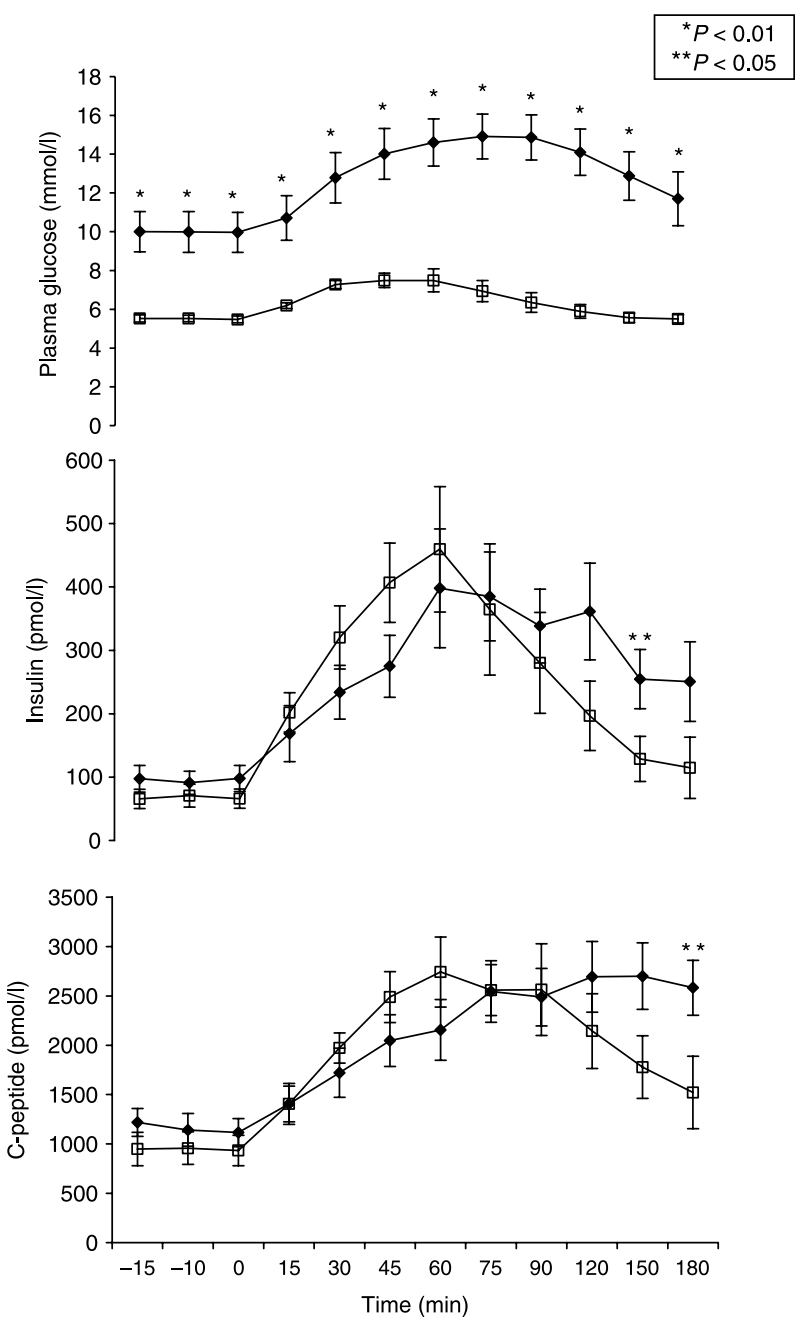

Figure 2 Plasma glucose- (upper panel), insulin- (middle panel) and C-peptide (lower panel) concentrations during ingestion of meal in type-2 diabetic patients (black diamonds) and matched control subjects (white squares). Mean \pm s.E.M. plasma DPP-IV activity had HbAlc levels of $8.0 \%$ or below $(17,18)$. However, in other patients with HbAlc levels below $8.5 \%$, increased (present study) or unchanged (present study, 15, 16) DPP-IV activity compared to controls was found. These apparent differences may simply be coincidental, arising from the natural variability together with the use of different methodology for assessing plasma DPP-IV activity. Nevertheless, as glucose control worsens, it seems that there is a connection between glycemia and DPP-IV activity, as indicated by the finding of a positive correlation between plasma DPP-IV activity and HbAlc levels in type-2 diabetes (present study), protocol one and Ref. (16) and between plasma DPP-IV activity and fructosamine concentrations in type-1 diabetes (33). Whether this is a primary or secondary effect is at present unclear, but hyperglycemia does not appear to affect DPP-IV enzymatic activity per se, as indicated from experiments, where the purified enzyme was incubated under high glucose conditions for up to 1 week $(16,34)$. In contrast, exposure to elevated glucose can increase DPP-IV gene expression, which in turn results in changes in levels of DPP-IV activity. Thus, Pala et al. (34) showed that mRNA for DPP-IV in human glomerular endothelial cells cultured in vitro with

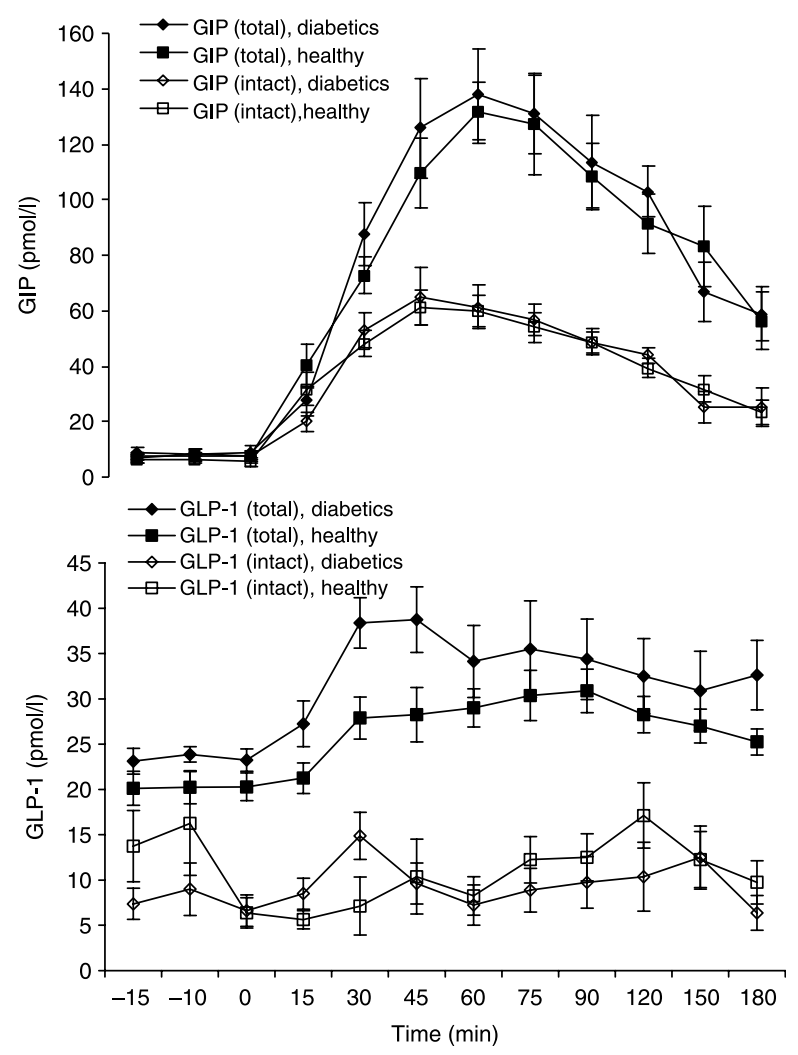

Figure 3 Incretin hormones during the meal ingestion: upper panel, total and intact glucose-dependent insulinotropic polypeptide (GIP) responses; and lower panel, total and intact glucagon-like peptide-1 (GLP-1) responses in type-2 diabetic patients (diamonds) and control subjects (squares). Mean \pm S.E.M. 


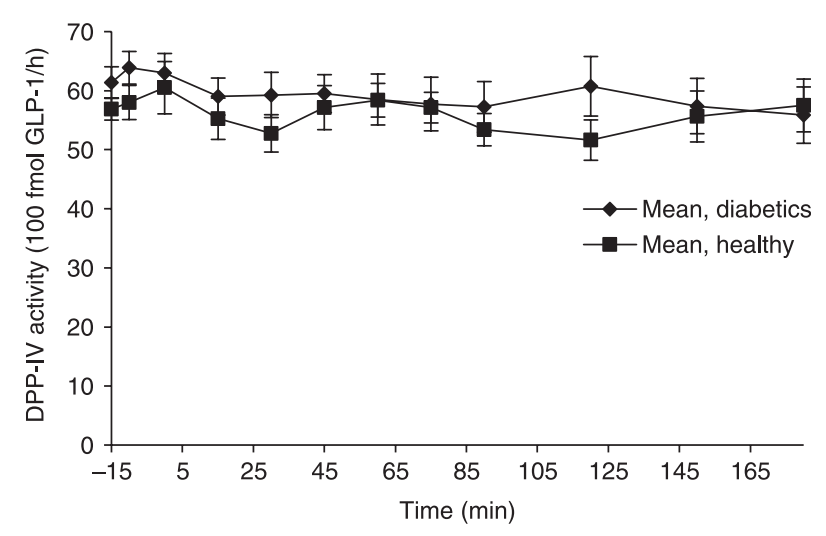

Figure 4 Plasma DPP-IV activity after meal ingestion in type-2 diabetic patients $(\diamond)$ and matched control subjects $(\boldsymbol{\square})$. Mean \pm S.E.M.

glucose increased dose-dependently with increasing glucose concentrations. This increased DPP-IV expression seemed, however, to be due to the associated hyperosmolarity of the incubation medium rather than the glucose per se, but nonetheless, hyperosmolarity could not account entirely for the effects of high glucose to increase endothelial DPP-IV activity, suggesting that additional mechanisms must also be involved (34).

Previous studies have suggested that some oral antidiabetic agents can alter soluble DPP-IV activity. Thus, both Lindsay et al. (22) and Lenhard et al. (21) reported that treatment with metformin was associated with reduced levels of DPP-IV activity in plasma or serum in vivo, and Lenhard et al. (21) also found that pioglitazone treatment resulted in similar reductions. The underlying mechanism of this action of metformin is controversial. Using in vitro activity assays, Lindsay et al. $(22,23)$ found that metformin inhibited DPP-IV activity, leading them to conclude that it behaves as a DPP-IV inhibitor by acting directly on the enzyme. In contrast, Hinke et al. (35), Yasuda et al. (24), and Lenhard et al. (21) were unable to influence the in vitro enzymatic activity, suggesting that neither metformin nor pioglitazone is a conventional competitive DPP-IV inhibitor. Metformin may, however, alter enzyme activity in a manner unrelated to competitive inhibition. For example, Lenhard et al. (21) suggested that these agents reduce the levels of the soluble form of the enzyme (and hence activity) by influencing secretion/ release of the membrane-bound enzyme to the blood. Metformin-associated increased levels of GLP-1 $(23,24)$ have been attributed both to stimulation of GLP-1 secretion (24) and reduced GLP-1 degradation (23). In the present study (protocol one), metformin did not appear to influence plasma DPP-IV activity, and there were no differences in the proportion of intact GLP-1 or GIP, supporting the conclusions of Hinke (35), Yasuda (24) and Lenhard (21) suggested that metformin does not act as a DPP-IV inhibitor. Although fasting GLP-1 levels (both intact and total) were not affected by metformin, interestingly, both intact and total GIP were elevated in the patients on metformin treatment (Table 2), suggesting that metformin may somehow stimulate K-cell secretion.

Short-term changes in glycemia, such as those associated with meal ingestion, seem not to acutely affect plasma DPP-IV activity (protocol two), supporting previous observations that the enzymatic activity is unchanged during the oral glucose tolerance test $(18,36)$. However, long-term exposure to changes in glycemia can alter DPP-IV activity, as indicated by the positive correlation between changes in HbAlc levels and plasma DPP-IV activity over time (16). This could reflect that a long-term response is required to change tissue DPP-IV expression (34), leading to altered DPP-IV activity, raising the possibility that increased DPP-IV activity may be functionally related to poor metabolic control.

In light of the finding that plasma DPP-IV activity is increased in type-2 diabetes, it is tempting to speculate that this may result in increased degradation of the incretin hormones, leading to an impaired incretin effect and ultimately a reduced insulin secretion and hyperglycemia. However, in the present study, this does not appear to be the case. Under fasting conditions, intact incretin concentrations were actually higher in the diabetic patients than in the control subjects, leading to increases in the ratios (intact as a proportion of total) in the patients, despite their higher plasma DPP-IV activity levels. This observation illustrates the caveat that has previously been suggested, namely that measurement of DPP-IV activity in the plasma may not necessarily reflect the degree of in vivo degradation of the incretin hormones by DPP-IV (37), particularly as this relates to the endogenously released peptides. This is because the N-terminal truncation of both GLP-1 and GIP in vivo proceeds much more rapidly than can be explained solely by the activity of the soluble form of enzyme in the plasma. On the contrary, it is much more likely that the membrane-bound DPP-IV (particularly that associated with the capillary endothelium in close proximity to the intestinal endocrine cells (38)) is responsible. In support of this, the half-life of both incretin hormones in human plasma is much longer in vitro than that found in vivo in humans $(2,31,39)$. Thus, in the present study, intact incretin hormone concentrations were elevated in the patients, which then may contribute to the hyperinsulinemia also present in these subjects. Previous studies from this laboratory showing that postprandial incretin concentrations, in particular GLP-1, are reduced in type-2 diabetes (11), seem at odds with the present observations of increased GLP-1 and GIP concentrations in the patients. However, this may reflect population and protocol differences between the two studies. Thus, in the study by Vilsbøll et al. (11), the patients were in poorer metabolic control (HbAlc of 9.2\%) and underwent a washout period of 3 days of oral hypoglycemic agents prior to the meal test. In contrast, in the present 
study, the patients had better metabolic control (HbAlc of $7.5 \%)$ and oral antidiabetic medication was continued until the evening prior to the study.

In summary, we found increased plasma DPP-IV activity in the fasting state of type- 2 diabetic patients. This was not associated with a decrease in active incretin hormones, suggesting that measurement of plasma DPP-IV activity does not provide a predictive index of in vivo endogenous incretin hormone degradation. A positive correlation between DPP-IV activity and HbAlc suggests that metabolic control may influence the level of DPP-IV activity as found by others. This, however, may require long-term exposure to high glucose concentrations. Thus, we found that DPP-IV activity is not acutely regulated after ingestion of a meal, suggesting that incretin release, rather than processing in the plasma, is responsible for acute changes in incretin levels observed during meal ingestion.

\section{Acknowledgements}

We thank Jytte Purtoft and Susanne Reimer for technical assistance and Lene Hansen for statistical support.

\section{References}

1 Deacon CF, Nauck MA, Toft-Nielsen M, Pridal L, Willms B \& Holst JJ. Both subcutaneously and intravenously administered glucagonlike peptide I are rapidly degraded from the NH2-terminus in typeII diabetic patients and in healthy subjects. Diabetes $1995 \mathbf{4 4}$ 1126-1131.

2 Deacon CF, Nauck MA, Meier J, Hucking K \& Holst JJ. Degradation of endogenous and exogenous gastric inhibitory polypeptide in healthy and in type 2 diabetic subjects as revealed using a new assay for the intact peptide. Journal of Clinical Endocrinology and Metabolism 200085 3575-3581.

3 Mentlein R. Dipeptidyl-peptidase IV CD26 - role in the inactivation of regulatory peptides. Regulatory Peptides 199985 9-24.

4 Pederson RA, Kieffer TJ, Pauly R, Kofod H, Kwong J \& McIntosh CH. The enteroinsular axis in dipeptidyl peptidase IV-negative rats. Metabolism 199645 1335-1341.

5 Deacon CF, Hughes TE \& Holst JJ. Dipeptidyl peptidase IV inhibition potentiates the insulinotropic effect of glucagon-like peptide 1 in the anesthetized pig. Diabetes 1998 47 764-769.

6 Deacon CF, Danielson P, Klarskov L, Olesen M \& Holst JJ. Dipeptidyl peptidase IV inhibition reduces the degradation and clearance of GIP and potentiates its insulinotropic and antihyperglycemic effects in anesthetized pigs. Diabetes 200150 1588-1597.

7 Pospisilik JA, Stafford SG, Demuth HU, Mcintosh CHS \& Pederson RA. Long-term treatment with dipeptidyl peptidase IV inhibitor improves hepatic and peripheral insulin sensitivity in the VDF Zucker rat - a euglycemic-hyperinsulinemic clamp study. Diabetes $2002512677-2683$.

8 Deacon CF, Ahren B \& Holst JJ. Inhibitors of dipeptidyl peptidase IV: a novel approach for the prevention and treatment of Type 2 diabetes? Expert Opinion on Investigational Drugs 200413 1091-1102.

9 Ahren B \& Schmitz O. GLP-1 receptor agonists and DPP-4 inhibitors in the treatment of type 2 diabetes. Hormone and Metabolic Research 200436 867-876.
10 Nauck M, Stockmann F, Ebert R \& Creutzfeldt W. Reduced incretin effect in type 2 non-insulin-dependent diabetes. Diabetologia 1986 29 46-52.

11 Vilsbøll T, Krarup T, Deacon CF, Madsbad S \& Holst JJ. Reduced postprandial concentrations of intact biologically active glucagonlike peptide 1 in type 2 diabetic patients. Diabetes 200150 609-613.

12 Weir GC, Mojsov S, Hendrick GK \& Habener JF. Glucagonlike peptide I (7-37) actions on endocrine pancreas. Diabetes 198938 338-342.

13 Vilsbøll T, Knop FK, Krarup T, Johansen A, Madsbad S, Larsen S, Hansen T, Pedersen $\mathrm{O} \&$ Holst JJ. The pathophysiology of diabetes involves a defective amplification of the late-phase insulin response to glucose by glucose-dependent insulinotropic polypeptideregardless of etiology and phenotype. Journal of Clinical Endocrinology and Metabolism $2003 \mathbf{8 8} 4897-4903$.

14 Vilsbøll T. On the role of the incretin hormones GIP and GLP-1 in the pathogenesis of Type 2 diabetes mellitus. Danish Medical Bulletin $200451364-370$.

15 Toft-Nielsen M, Damholt M, Hilsted J, Hughes TE, Krarup T, Madsbad S \& Holst J. GLP-1 secretion is decreased in NIDDM patients compared to matched control subjects with normal glucose tolerance. Diabetologia 1999 A40 143.

16 Manucci E, Pala L, Ciani S, Bardini G, Pezzatini A, Sposato I, Cremasco F, Ognibene A \& Rotella C. Hyperglycaemia increases dipeptidyl peptidase IV activity in diabetes mellitus. Diabetologia $2005 \mathbf{4 8} 1168-1172$.

17 Korosi J, Mcintosh CHS, Pederson RA, Demuth HU, Habener JF, Gingerich R, Egan JM, Elahi D \& Meneilly GS. Effect of aging and diabetes on the enteroinsular axis. Journals of Gerontology Series A, Biological Sciences and Medical Sciences 200156 M575-M579.

18 Meneilly GS, Demuth HU, Mcintosh CHS \& Pederson RA. Effect of ageing and diabetes on glucose-dependent insulinotropic polypeptide and dipeptidyl peptidase IV responses to oral glucose. Diabetic Medicine 200017 346-350.

19 Nagata T, Umeda Y, Urakami M \& Inada M. Urinary dipeptidyl peptidase IV U-DAP IV activity in patients with impaired glucose tolerance and diabetes mellitus. Journal of Japanese Diabetes Society 198831 169-171.

20 Takasawa M, Kasahara S, Ikarashi K, Nakamura H, Tuda A, Ito S \& Shibata A. Urinary glycylprolyl dipeptidylaminopeptidase activity in diabetes mellitus. Journal of Japanese Diabetes Society $199033287-291$.

21 Lenhard JM, Croom DK \& Minnick DT. Reduced serum dipeptidyl peptidase-IV after metformin and pioglitazone treatments. Biochemical and Biophysical Research Communications 2004324 92-97.

22 Lindsay JR, Duffy NA, McKillop AM, Ardill J, O’Harte FPM, Flatt PR \& Bell PM. Inhibition of dipeptidyl peptidase IV activity by oral metformin in Type 2 diabetes. Diabetic Medicine 200522 654-657.

23 Mannucci E, Ognibene A, Cremasco F, Bardini G, Mencucci A, Pierazzuoli E, Ciani S, Messeri G \& Rotella CM. Effect of metformin on glucagon-like peptide 1 (GLP-1) and leptin levels in obese nondiabetic subjects. Diabetes Care 200124 489-494.

24 Yasuda N, Inoue T, Nagakura T, Yamazaki K, Kira K, Saeki T \& Tanaka I. Enhanced secretion of glucagon-like peptide 1 by biguanide compounds. Biochemical and Biophysical Research Communications $2002 \mathbf{2 9 8} 779-784$.

25 World Health Organization. Definition, diagnosis and classification of diabetes mellitus and its complications. Part 1. Diagnosis and classification of diabetes mellitus. Geneva: Department of Noncommunicable Disease Surveillance, 1999.

26 Ørskov C, Rabenhoj L, Wettergren A, Kofod H \& Holst JJ. Tissue and plasma concentrations of amidated and glycine-extended glucagon-like peptide I in humans. Diabetes 1994 43 535-539.

27 Vilsbøll T, Krarup T, Sonne J, Madsbad S, Volund A, Juul AG \& Holst JJ. Incretin secretion in relation to meal size and body weight in healthy subjects and people with type 1 and type 2 diabetes mellitus. Journal of Clinical Endocrinology and Metabolism $2003 \mathbf{8 8}$ 2706-2713. 
28 Wilken M, Larsen FS, Buckley D \& Holst JJ. New highly specific immunoassays for glucacon-like peptide 1 GLP-1. Diabetologia 199942 A196.

29 Krarup T, Madsbad S, Moody AJ, Regeur L, Faber OK, Holst JJ \& Sestoft L. Diminished immunoreactive gastric inhibitory polypeptide response to a meal in newly diagnosed type I insulindependent diabetics. Journal of Clinical Endocrinology and Metabolism 198356 1306-1312.

30 Krarup $\mathrm{T} \&$ Holst JJ. The heterogeneity of gastric inhibitory polypeptide in porcine and human gastrointestinal mucosa evaluated with five different antisera. Regulatory Peptides 19849 35-46.

31 Deacon CF, Johnsen AH \& Holst JJ. Degradation of glucagon-like peptide-1 by human plasma in vitro yields an N-terminally truncated peptide that is a major endogenous metabolite in vivo. Journal of Clinical Endocrinology and Metabolism $1995 \mathbf{8 0}$ 952-957.

32 Pauly RP, Rosche F, Wermann M, Mcintosh CHS, Pederson RA \& Demuth HU. Investigation of glucose-dependent insulinotropic polypeptide-1-42 and glucagon-like peptide-1-7-36 degradation in vitro by dipeptidyl peptidase IV using matrix-assisted laser desorption/ionization time of flight mass spectrometry - a novel kinetic approach. Journal of Biological Chemistry 1996271 23222-23229.

33 Nukada O, Kobayashi M, Moriwake T, Kanzaki S, Himei H, Yoda T \& Seino Y. Urinary glycylprolyl dipeptidyl aminopeptidase GP-DAP in insulin-dependent diabetic patients. Acta Paediatrica 199281 907-911.

34 Pala L, Mannucci E, Pezzatini A, Ciani S, Sardi J, Raimondi L, Ognibene A, Cappadona A, Vannelli BG \& Rotella CM. Dipeptidyl
peptidase-IV expression and activity in human glomerular endothelial cells. Biochemical and Biophysical Research Communications $2003 \mathbf{3 1 0} 28-31$.

35 Hinke SA, Kuhn-Wache K, Hoffmann T, Pederson RA, Mcintosh CHS \& Demuth HU. Metformin effects on dipeptidylpeptidase IV degradation of glucagon-like peptide-1. Biochemical and Biophysical Research Communications 2002291 1302-1308.

36 Gunnarsson T, Sorhede-Winzell M, Deacon CF, Larsen MO, Jelic K, Carr RD \& Ahren B. Differential GIP and GLP-1 release following pure protein ingestion in mice. Diabetologia $2005 \mathbf{4 8}$ A203.

37 Deacon CF \& Holst JJ. Dipeptidyl peptidase IV inhibitors: a promising new therapeutic approach for the management of type 2 diabetes. International Journal of Biochemical and Cell Biology 200638 831-844.

38 Hansen L, Deacon CF, Ørskov C \& Holst JJ. Glucagon-like peptide-1-(7-36)amide is transformed to glucagon-like peptide1-(9-36)amide by dipeptidyl peptidase IV in the capillaries supplying the L cells of the porcine intestine. Endocrinology 1999140 5356-5363.

39 Meier JJ, Nauck MA, Kranz D, Holst JJ, Deacon CF, Gaeckler D, Schmidt WE \& Gallwitz B. Secretion, degradation, and elimination of glucagon-like peptide 1 and gastric inhibitory polypeptide in patients with chronic renal insufficiency and healthy control subjects. Diabetes 200453 654-662.

Received 28 February 2006

Accepted 30 May 2006 